\title{
Congolese People Practices towards Insalubrity in the Mombele District
}

\author{
Francy Pembi ${ }^{*}$, Kamuanga Palamba Thomas ${ }^{2}$, Mazyambo Alumbangala Baudouin ${ }^{1}$ \\ ${ }^{1}$ Faculty of Science, Department of the Environment, University of Kinshasa, Kinshasa, Democratic Republic of Congo \\ ${ }^{2}$ Tshikapa Higher Pedagogical Institute, Department of Management and Administration of Educational and Training Institutions \\ (GAIF), Tshikapa, Democratic Republic of Congo \\ Email: ^francypembi@gmail.com
}

How to cite this paper: Pembi, F., Thomas, K.P. and Baudouin, M.A. (2022) Congolese People Practices towards Insalubrity in the Mombele District. Open Journal of Ecology, 12, 133-148.

https://doi.org/10.4236/oje.2022.122008

Received: December 11, 2021

Accepted: January 27, 2022

Published: January 30, 2022

Copyright (c) 2022 by author(s) and Scientific Research Publishing Inc. This work is licensed under the Creative Commons Attribution International License (CC BY 4.0).

http://creativecommons.org/licenses/by/4.0/ (c) (i) Open Access

\begin{abstract}
Introduction: Behaviour of many people in Mombele district is out of good hygiene practices related to waste management for reducing the environmental health risks. Thus, this study aimed to assess the practices related to insalubrity at Mombele district in Democratic Republic of Congo. Methods: To get results from this quantitative investigation, we used observation and survey as methods. Yet, a sample of 384 households helped to get results during the period from August $15^{\text {th }}$ to October $15^{\text {th }}, 2020$. Results: The insalubrity is almost found everywhere. For respondents, it is seen through wild landfill (37.8\%); wastes are thrown anywhere (59.4\%); the main reason of this practice is the lack of dustbins (28.3\%); the attitude towards insalubrity is positive (52.3\%). There is a significant difference between the educational level, occupational categories, monthly incomes and the practice of throwing waste anywhere ( $\mathrm{p}$ value $<0.05)$. Conclusion: Throughout the results, we say that the population from Mombele neighborhood hardly fears the insalubrity, because the majority of respondents find normal the practice of throwing wastes anywhere. This practice highlights that they do not fear the consequences that may affect the environment and the human health.
\end{abstract}

\section{Keywords}

Behaviour, Insalubrity, People

\section{Introduction}

The unsanitary environment characterised by the presence of refuse and poor environmental hygiene due to the behaviour of the population, is a non-neglected situation that should interest everyone, taking into account its multiple conse- 
quences to health and environment. Mankind needs to live with others. Thus, it must respect the quality of life of each person through its environmental practices. It should be noted, however, that urbanisation, especially in developing countries, is unfortunately accompanied by the phenomenon of insalubrity which makes man vulnerable to various pathologies, which are avoidable with hygiene practices.

The World Health Organization (WHO) report in 2016 already Stated that up to $24 \%$ of diseases in the world are caused by environmental exposures that can be avoided. This report estimates that over 33\% of illnesses affecting children under 5 are caused by these exposures [1]. Of course, the populations' health depends on the state of the physical environment in which they live. Unfortunately, man is the main actor or agent of the permanent degradation of the environment. This implies that, to have a healthy environment, man must be conscious of his behaviour so as not to favour the emergence of various diseases already known such as malaria, cholera, and those whose parasites are responsible for the diarrhea, respiratory and skin infections, etc.

The deficiencies observed in the various fields necessary for the management of public sanitation give urban spaces unsanitary conditions which are one of health risks factors. Thus, Stren et al. quoted by Matadi, point out that the management of the urban living environment poses many problems in developing countries, especially for those which do not have the sanitation facilities and efficient policy. Uncontrolled urbanisation exacerbates this situation due to its speed and lack of control. In black Africa, the problem is all the more serious as most countries are very poor and do not have sufficient resources to cope with increasing urbanisation [2].

Regarding to its irreversibility, urbanisation is becoming more and more protean in cities where it is not under control, with sometimes unavoidable environmental consequences. This is reflected in extended or existing neighborhoods lacking basic services and consuming space that is harmful to the environment. Savané and P. Antoine were already sounding the alarm: "In developing African cities, several factors make it difficult to control sanitation management. This control is difficult because strong demographic growth is accompanied by unbridled spatial development that escapes all control of planners [3]."

The populations settle in spaces without having the possibility of accessing urban facilities and services. Thus, health management becomes very difficult with multiple and varied landscapes. Environmental degradation and insalubrity constitute the most immediately visible face of the deep inadequacies of collective management of space, the deficiencies and shortages of public services, the impoverishment of the greatest number of people; brief, an urban transition that would take place in pain [4]. These problems have as a corollary, the development of precarious housing and result in the degradation of the environment, the expansion of unsanitary conditions and the lack of hygiene, especially in under-integrated neighborhoods [5]. These problems potentially have impacts 
on the health of urban populations.

The city of Kinshasa in general is facing "uncontrolled urbanisation" linked in particular to the lack of a real policy of national land use planning and urban planning. It has become an anthropo-ecosystem whose environmental aesthetics are a poor relation. Insalubrity has become a real scourge that is plaguing it. Former nicknamed "Kinshasa the beautiful", today the Congolese capital has become "Kinshasa the trash". Rubbish is littered almost all over the city.

The provincial city of Kinshasa can be considered today as a megalopolis of insalubrity, where not everyone is sensitive to environmental issues. Most of the gutters are either blocked or non-existent depending on the neighborhood. The increase in insalubrity and the degradation of this ecosystem have taken on worrying and dangerous proportions for the Kinshasa population. Insalubrity shares daily life with populations whose attitude is either resignation or indifference.

For some observers, the inhabitants of the city of Kinshasa in general and, of the Mombele district in particular, are not conscious of the danger that awaits them. For others, it is the State or Government that is the responsible of all this. However, looking at practices related to unsanitary conditions, from an almost ethological perspective is essential. In this article, we want to determine the practices related to unsanitary conditions. To do this, the question that guided this research is: how does the population of the Mombele district behave towards insalubrity? The answer to this question will make it possible to suggest some solutions for changing the behaviour of this population.

\section{Materials and Methods}

\subsection{Study Area}

This study took place in the Mombele district, municipality of Limete, city of Kinshasa province. Mombele camp, commonly known as Mombele district, is subdivided into five sub-districts. They are: Mombele, Mayulu, Mfumu Mvula, Mateba and Agricole. Mombele district is located to the southwest of the Municipality of Limete.

The name Mombele comes from the name of the leader of a political party. Mombele was a Teke village and this is what justifies the presence of a lot of teke in this district. It was around 1961 that the village of Mombele was annexed to the City of Kinshasa. Mombele Pierre, customary chief and head of the political party of the Union of Bateke (UNIBAT), had claimed to have had the approval of the Minister of the colonies, on the return of the Round Table in Belgium, for the subdivision of the district. This district, like others, has avenues and streets [6]. Figure 1 shows the Mombele district and its localities.

The climate of the studied area is characterized by the rhythms and frequency of precipitation as the city of Kinshasa. According to Koppen's classification, the entire Kinshasa region is characterized by a humid tropical climate AW4, one rainy season and one dry season lasting four months. The rainy season runs 




Figure 1. Map of the study area. 
from September to mid-May, with a slight fluctuation from December to February. On the other hand, the dry season goes from June to September. During this period, there is a virtual absence of rains [7].

The natural vegetation cover has been destroyed by man. There are certain plants such as papaya, avocado, mango... Certain food products such as peanuts, eggplants, onions, "ndembi", amaranths, cabbages, peppers, sweet potatoes, cassava, various vegetables are cultivated there.

Biophysics has facilitated human settlement, but since there has been almost no urbanisation in the true sense of the term regarding various environmental issues.

\subsection{Methods}

\subsubsection{Type of Study and Sampling Techniques}

This is a descriptive study for analytical purposes. We proceeded by stratified probability sampling (each avenue being considered as a stratum). The inhabited plot was defined as the unit to be surveyed and the household is the statistical unit of the survey. To do this, the choice of the target population was based on the following selection criteria: is considered to be part of the target population, any member of the household who is at least 18 years old, located in the geographical territory of the Mombele district at the time of the survey, and have lived there for at least one year. In total, 384 households were surveyed by applying the formula: $n=\frac{Z^{2} * p * q}{d^{2}}$ [8].

$$
n=\frac{1.96^{2} * 0.5 * 0.5}{0.05^{2}}=384 \text { subjects }
$$

To determine this sample, we proceeded by simple two-stage random drawing. In the first degree, out of 40 avenues in the district and taking into account certain constraints, 17 avenues were selected at random from a list using the ballot box method. At the second stage, to reach the stratum of each avenue, we proceeded by the sampling step by dividing the total number of households considered as plots by the size of the sample, i.e. 13,581/384, which gives a step of survey of 35 . Knowing that there would be certain households which could reject to collaborate with us, and that there would be badly filled out forms, this survey step was reduced to 10 .

\subsubsection{Data Collection Techniques}

The data was collected by means of a survey questionnaire administered to households in the Mombele district. This questionnaire was pretested to four persons from another district so that ununderstood questions may be reviewed. The data collection was related to behaviour of unsanitary conditions. They therefore helped as an essential support in the conception of the perspectives. Four investigators were trained and deployed to the field for a month. The interview took 15 to 30 minutes (20 minutes on average).

\subsubsection{Data Analysis}

The data obtained from questionnaire was analyzed using simple percentages 
and chi-square tests. The SPSS 20.1 software helped to do it. The significance level confidence interval was $\mathrm{p}$ value $<0.05$. These statistical methods were used to describe the population behaviour towards insalubrity for important making decision.

\section{Variables of interest}

The variables of interest targeted in this study are:

- Characteristics of the participants: level of education, socio-professional categories and monthly income;

- Practices related to unsanitary conditions: bad personal waste management which creates poor sanitation and involves disease vectors.

\section{Results}

The following results are based on a sample of 384 respondents.

\subsection{Demographic and Social Characteristics of Respondents}

Some characteristics of the respondents (level of education, socio-professional categories, level of monthly income and household size) are displayed in Table 1.

Table 1. Profile of respondents.

\begin{tabular}{|c|c|c|c|}
\hline Variable & Modalities & Frequency $(\mathrm{n}=384)$ & Pourcentage \\
\hline \multirow[t]{4}{*}{ Level of education } & Illiterate & 8 & 2.1 \\
\hline & Primary/lower & 14 & 3.6 \\
\hline & Secondary & 239 & 62.2 \\
\hline & Higher & 123 & 32.0 \\
\hline \multirow[t]{5}{*}{ Occupation } & Civil/Public servant & 44 & 11.5 \\
\hline & Company executive & 3 & 0.8 \\
\hline & Private employee & 58 & 15.1 \\
\hline & Unemployed & 53 & 13.8 \\
\hline & Informal & 226 & 58.9 \\
\hline \multirow[t]{4}{*}{ Monthly income } & Less than $100 \$$ & 194 & 50.5 \\
\hline & 100 to $199 \$$ & 99 & 25.8 \\
\hline & 200 to $299 \$$ & 51 & 13.3 \\
\hline & More than $300 \$$ & 39 & 10.2 \\
\hline \multirow[t]{5}{*}{ Household size } & $3-5$ & 32 & 8.3 \\
\hline & $6-8$ & 178 & 46.4 \\
\hline & $9-11$ & 156 & 40.6 \\
\hline & $12-14$ & 14 & 3.6 \\
\hline & $15-17$ & 4 & 1.0 \\
\hline Average size & $8.1 \pm 1.94$ & & \\
\hline
\end{tabular}


The study results of Table 1 show that $62.2 \%$ of respondents have a secondary education level, $32 \%$ higher and $3.6 \%$ primary/lower level. These different levels of education may indicate that the numerical importance of schools can make the understanding of environmental hygiene standards easy to assimilate.

However, it appears that $58.9 \%$ of the respondents live of the informal sector to meet their needs, $15.1 \%$ are in the private sector and $11.5 \%$ are civil servants. These socio-professional categories are, in particular, the expression of underdevelopment. This can make it difficult to monitor behaviour related to healthy environment.

More than half of the respondents (50.5\%) live with a monthly income of less than $\$ 100,25.8 \%$ between $\$ 100$ and $\$ 199$ and $13.3 \%$ between $\$ 200$ and $\$ 299$. The various monthly incomes mentioned can be explained especially by the poor wage policy and unemployment. They constitute a factor of poverty which cannot allow to reach the two ends of the month, and which is an important determinant of unsanitary conditions. Poverty always has a negative impact on the health of households.

The most dominant household size is between 6 to 8 people (46.4\%) followed by 9 to $11(40.6 \%)$ and the average is 8 people per household. This average can point out that family planning is a problem in the studied area and in addition, it could be the consequence of the African culture which would like members of the extended family to live together. These phenomena can be the source of irresponsible environmental behaviour or unsanitary conditions.

\subsection{Behaviour Related to Insalubrity}

Some ways of behaving towards insalubrity by the population of the Mombele district are shown in Table 2 to allow associations to be established.

The results obtained in Table 2 suggest that the respondents have some knowledge of the manifestations of unsanitary conditions: $37.8 \%$ of them evoke open dumping, $27.3 \%$ stagnant water and $22.9 \%$ clogged gutters. These different points of view seem close to reality. Figure 2 is, among other things, an expression of the insalubrity in the Mombele district and demonstrates the irresponsibility of the State.

During outings or walks, $59.4 \%$ of the respondents throw/dispose garbage anywhere, ignoring that throwing garbage anywhere has consequences for the environment and for health. Also, $14.1 \%$ take them home and $10.4 \%$ throw them where they find rubbish. These practices are not recommended and can be explained, in particular by the culture of each inhabitant and the lack of environmental education.

However, it should be noted that the respondents justify their behaviour of throwing/disposing waste anywhere in different ways. Among them, 52.1\% throw them away for lack of public dustbins, for $17.2 \%$, it is not up to them to develop the city, $10.7 \%$ evoke the habits of all, $7.6 \%$ what everyone does. These 
Table 2. Environmental unhealthy behaviour.

\begin{tabular}{|c|c|c|c|}
\hline Variable & Modalities & $\begin{array}{c}\text { Frequency } \\
(\mathrm{n}=384)\end{array}$ & Pourcentage \\
\hline \multirow{6}{*}{$\begin{array}{l}\text { Manifestation of } \\
\text { insalubrity in your } \\
\text { district }\end{array}$} & Through open dumping & 145 & 37.8 \\
\hline & Through stagnant water & 105 & 27.3 \\
\hline & Through clogged gutters & 88 & 22.9 \\
\hline & By uncured streams & 6 & 1.6 \\
\hline & Through unpleasant smells & 38 & 9.9 \\
\hline & Nothing & 2 & .5 \\
\hline \multirow{6}{*}{$\begin{array}{l}\text { Waste disposal site } \\
\text { during outings or } \\
\text { walks }\end{array}$} & Anywhere & 228 & 59.4 \\
\hline & Where I find rubbish & 40 & 10.4 \\
\hline & Put in the public dustbin & 15 & 3.9 \\
\hline & Look for a stream & 19 & 4.9 \\
\hline & In a gutter & 28 & 7.3 \\
\hline & Take it home & 54 & 14.1 \\
\hline \multirow{7}{*}{$\begin{array}{l}\text { Reasons for } \\
\text { anywhere }\end{array}$} & It's my right & 9 & 2.3 \\
\hline & It's not my duty to manage the city & 26 & 6.8 \\
\hline & It's not forbiden & 22 & 5.7 \\
\hline & Everyone does it & 29 & 7.6 \\
\hline & These are our habits & 41 & 10.7 \\
\hline & When I see others doing it & 17 & 4.4 \\
\hline & Due to lack of public dustbins & 109 & 28.4 \\
\hline \multirow{3}{*}{$\begin{array}{l}\text { Attitude towards } \\
\text { insalubrity }\end{array}$} & Negative & 84 & 21.9 \\
\hline & Positive & 201 & 52.3 \\
\hline & Indifférence & 99 & 25.8 \\
\hline
\end{tabular}

justifications are probably explained by the ignorance of green culture, but also by the absenteeism of the State or Government which should be the guarantor in this matter.

Regarding the attitude of the respondents towards unsanitary conditions, the results indicate that the majority of the subjects surveyed, $52 \%$ have a positive attitude towards unsanitary conditions (like insalubrity) against $22 \%$ who are not favorable and $26 \%$ who are indifferent. This is justified by cultural diversity and sometimes by a conscience that is not formed in Eco ethics. Figure 3 is one of the proofs of this negative attitude to food safety. Preparing or consuming food in an unsanitary environment is hardly a nuisance in the municipality studied.

The relation of variables is displayed in Table 3. 




Figure 2. View of insalubrity in the Mombele district.

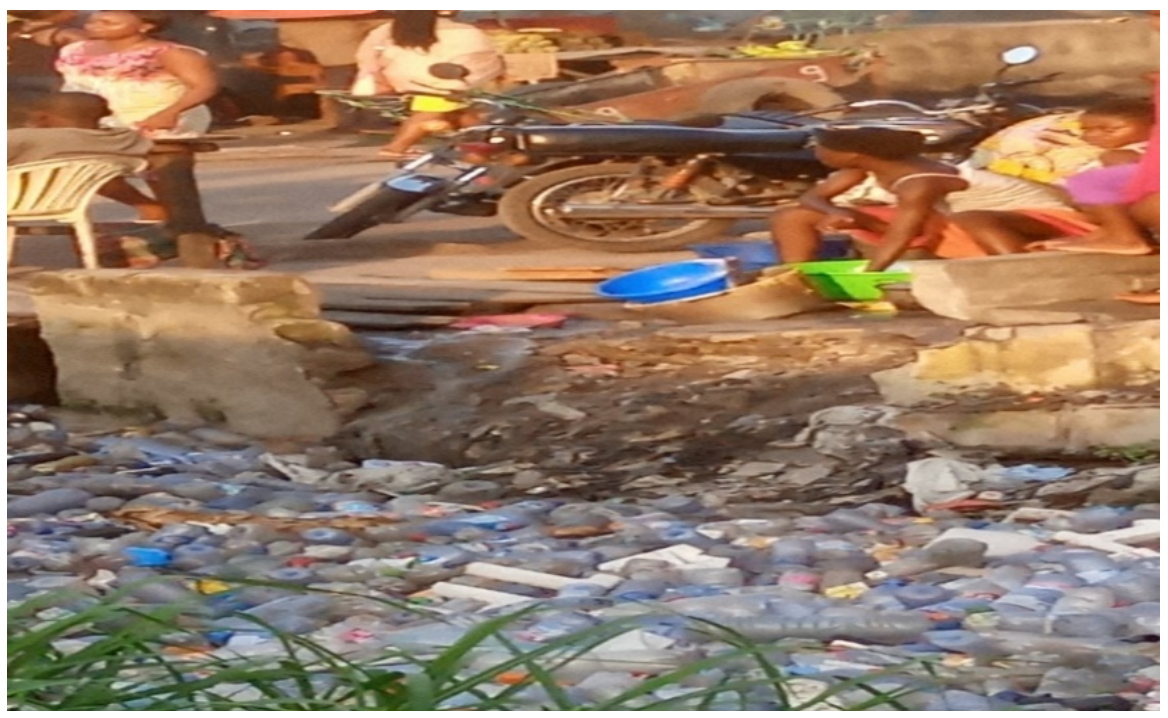

Figure 3. View of a saleswoman in the makeshift restaurant next to a polluted stream.

Table 3. Chi-squared analysis.

\section{Waste disposal site during outings or walks}

Level of education

Chi-square $=51,179, \mathrm{p}=0.000$

Waste disposal site during outings or walks

\begin{tabular}{|c|c|c|c|c|c|c|c|}
\hline & Anywhere & $\begin{array}{l}\text { Where I find } \\
\text { rubbish }\end{array}$ & $\begin{array}{c}\text { Put in the public } \\
\text { dustbin }\end{array}$ & $\begin{array}{c}\text { Look for a } \\
\text { stream }\end{array}$ & In a gutter & Take it home & Total \\
\hline Illiterate & 7 & 1 & 0 & 0 & 0 & 0 & 8 \\
\hline Primary & 13 & 1 & 0 & 0 & 0 & 0 & 14 \\
\hline Secondary & 163 & 19 & 9 & 7 & 10 & 31 & 239 \\
\hline Highier & 45 & 19 & 6 & 12 & 18 & 23 & 123 \\
\hline
\end{tabular}




\section{Continued}

\begin{tabular}{|c|c|c|c|c|c|c|c|}
\hline \multicolumn{8}{|c|}{$\begin{array}{l}\text { Socioprofessionnelle categories } \\
\text { Chi-square }=85,031 ; \mathrm{p}=0.000\end{array}$} \\
\hline Public servant & 16 & 6 & 1 & 5 & 4 & 12 & 44 \\
\hline Company executive & 0 & 0 & 1 & 1 & 0 & 1 & 3 \\
\hline Private employee & 14 & 9 & 4 & 4 & 10 & 17 & 58 \\
\hline Unemployee & 44 & 3 & 1 & 2 & 1 & 1 & 53 \\
\hline Indépendant & 154 & 22 & 8 & 7 & 13 & 22 & 226 \\
\hline \multicolumn{8}{|c|}{$\begin{array}{c}\text { Monthly income } \\
\text { Chi-square }=87,707 ; \mathrm{p}=0.000\end{array}$} \\
\hline Less than $100 \$$ & 147 & 14 & 5 & 6 & 6 & 16 & 194 \\
\hline 100 to $299 \$$ & 57 & 13 & 2 & 6 & 9 & 12 & 99 \\
\hline Over $300 \$$ & 24 & 13 & 8 & 7 & 13 & 26 & 91 \\
\hline
\end{tabular}

The difference observed in Table 3 is statistically very significant between the place of waste discharge anywhere and the level of education $(p<0.001)$, the socio-professional category $(\mathrm{p}<0.001)$ and the monthly income of the respondents $(p<0.001)$. It should be noted that these characteristics should be taken into account in the solid waste management and the State must find suitable solutions.

\section{Discussion}

This study is based on behaviour related to insalubrity in the Mombele district. Considering the study results, $62.2 \%$ of respondents were of secondary school level. Our results corroborate those of J. Matadi who observed that $54.4 \%$ of respondents were of secondary level [2]. From these results, we can consider that the level of education is an important indicator in the analysis of environmental situations as well as in the proposal of appropriate solutions. With this level, it should be indicated that the respondents are able to provide the information sought and are able to adopt responsible behaviour in matters of health. Moreover, Mpuru, in his study entitled "Kwilu: a disputed commercial space", indicates that the majority of heads of household in Kikwit IV municipality had a primary/lower level of education, followed by a secondary level. This contrast may be explained by the living environment. In DRC, the accessibility rate to education is still low for those living in sub-urban areas. This is probably due to the reduced number of educational institution infrastructure [9].

Regarding to occupation, 58.9\% lived in the informal sector (self-employed) and $50.5 \%$ had an income range of less than $\$ 100$ per month (Table 2). Yet, according to the report of the Ministry of National Economy quoted by Lelo Nzuzi, it should be noted that: at the time, Kinshasa city, capital of DRC had more industries and activities than the rest of the cities of the country. It had itself 169 industries in 1970. Kinshasa economy experienced its second death after 
that caused by the nationalizations of 1974. Indeed, after Zairianization, Kinshasa industry operated below $45 \%$ of its installed capacity, except breweries and the monthly income under $\$ 300$ a month which cannot meet the needs of the family [10]. Thus, we agree with UN-Habitat, in its report of the third session of the World Urban Forum, which recommends the following: it would be "benefit" to correct intra-urban inequalities. It is not surprising, under these conditions, to observe the virtual non-existence of public services in disadvantaged neighborhoods [11]. I. Sy, in his study on "the management of sanitation in Rufisque (Senegal): Sanitary issues and urban practices" indicates that, the modern sectors in crisis (public administration, private companies) employ only a small part of the active population. The informal economy appears to be a response to the employment needs of a growing urban population, faced with an insufficiently dynamic modern sector [5].

Concerning the monthly income, it is less than $\$ 100$ per month (50.5\%). R. Banza, in his study conducted in Cameroon, asserted that low monthly income is a determinant that often has a negative influence on health. When you have almost no financial means, it is difficult to control your behaviour in terms of health and the environment [12]. Following this reasoning, L. Binzangi points out that: poverty is on the basis of many environmental problems in cities. According to this author, when you are poor, you are unable to build according to urban planning standards and especially to manage well your environment. Therefore, a monthly income of less than $\$ 300$ cannot meet the needs of the family [13].

The average of household size is 8.1. J. Matadi's study reports that the respondents belonged to households whose size varied between 3 and 10 people, with an average of 6.5 people per household [2]. From the results of the MICS2 survey carried out by UNICEF in 2001 over the whole of the DRC, it is stated that Congolese households had an average of 6 people and nearly half were made up of 7 people or more. This indicates a diversity of socio-cultural and socioeconomic conditions [14].

Moreover, population growth has consequences for the environment. In this regard, we can show a few phenomena that can already be observed in the Mombele district, such as:

- spatial extension towards areas not allowed;

- densification of the district;

- a good number of households live in informal "non-development" dwellings;

- existing plots in full fragmentation;

- growing insecurity ("koulouna" phenomenon);

- insufficient basic infrastructure;

- emergence of environmental diseases;

- unsanitary conditions along all avenues;

- health risks little feared by many residents, etc.

The development context study of an urban space, especially in Africa, gener- 
ates insalubrity. Waste is produced, but above all, it is not well managed. The population responsible for it sometimes engages in uncontrolled behaviour to the detriment of the environment. Insalubrity results, of course, from the behaviour of the persons, but also from the chronic deficit in terms of facilities and infrastructure. This is revealed through the accumulation of innumerable discharges of wastewater and illegal dumps of district refuse in the areas of homes or places of life [14]. This Statement agrees with the results of this survey which found that for $37.8 \%$ of respondents, unsanitary conditions are noticed through illegal dumping.

Results from the study area indicate that the majority of respondents, when they go out (for walks) throws waste anywhere (59.4\%). The main reason for this practice is the lack of public dustbins. The high score for dumping waste anywhere borders on unsanitary conditions and its corollaries. The urban authority must have a watchful eye, vigilance (eco vigilance) on all forms of intervention by city dwellers, in order to preserve the public health of the populations. Public transit or final landfills should therefore constitute strategies in the process or stages of rational and responsible waste management in urban areas. Clearly, dumping waste anywhere remains the source of much harm to the environment and to human health.

According to the World Health Organization, suitable housing should also be equipped with basic infrastructure, in particular, water supply, sanitation, waste collection located in an environment of suitable quality from an ecological point of view and sanitary [12]. Based on this reasoning, Munkuamo says that in cities, sanitation is a support of life; it is on the list of Millennium Development Goals (MDGs) [7]. From these results, Anthony J. and McMichael, quoted by Baya, observe that the inhabitants are at the mercy of all kinds of sources of pollution, of the absence of means of sanitation (exposure to human excreta and unsafe water drink), exposure to hazardous synthetic organic chemicals in air, food and water [14].

Thus, on can read this through positive attitude to unsanitary conditions (Table 2). The report of the Office of the WHO Representative for Congo Brazzaville in 2003 observed the same problems as those raised by our survey in Mombele on this subject. This report shows that nearly half of the population copes with a life in unsanitary conditions nowadays without noticing/fearing any health risk [15]. Stéphane Zumsteeg, quoted by R. Baya, agrees with us by his observation made in his study that, the French, all socio-professional categories combined, even after having submitted a whole list of potential threats to health in their home (exterior noise, asbestos, humidity, dust mites, etc.), more than three quarters of the inhabitants do not think that their health is threatened today in their home ( $42 \%$ do not even think so "not at all") [14].

Observation of the difference between variables (Table 3) pointed out that there is a statistically very significant relationship between the level of education, the socio-professional category/occupation, the monthly income of the respon- 
dents and the act of throwing/disposing waste anywhere. where ( $\mathrm{p}$ value $<0.05$ ). These results go along with the WHO quoted by R. Banza Katshekewa which points out that, the way in which the man perceives the risks and reacts to them is involved by his experience and by the information and values from the family, the society and rulers. The behaviour of individuals and their lifestyle have an immediate or apparent influence on their health. These practices are themselves linked [...] to the physical, economic and social environment in which we operate [12].

\section{Perspectives}

The ecological perspective that drives us here is to consider taking into account the socio-cultural context to put in place, in a structured way, the relationship between attitude, practice, behaviour and the health risks related to insalubrity, especially that, the protection of the environment has become one of the major challenges of the $21^{\text {st }}$ century to respond to the right to the city, urbanity and eco-citizenship.

David Harvey, quoted by R. Spizzichino, points out that: "the right to the city is therefore not merely an individual right of access to the resources handed by the city; it is a right to change ourselves by changing the city in such a way as to make it more close to our dearest desire [16]". According to Henri Lefebvre to whom we owe this notion, quoted by C. Reiss, the right to the city is a "right to urban life, to renewed centrality, to places of meetings and exchanges, to the rhythms of life and timetables allowing the full and complete use of these moments and places" [17].

If everyone considered the Mombele district as a common good that must be accessible to all and that must be protected, it will become a pleasant place for meetings and exchanges. By exercising its ecological consciousness, the study area will change and become more in accordance with everyone's desire.

In addition to the right to the city, urbanity refers in the current sense, to a quality of individuals behaving in a polite manner with others. It thus appears as a characteristic of the city, the space of which is organized to facilitate all forms of interaction as much as possible [18]. S. Beucher and M. Reghezza point out that, city life can be manifested by a certain practice of urban space; it is above all a matter of individual psychology (it is a character of the inhabitants of cities, not of cities as a space) [19].

Thus, urbanity is "living in the city" which must lead to the notion of "urban culture". To do so, the population of the Mombele district must learn the culture of the environment respect in terms of sanitation, in order to spare other citizens from diseases related to insalubrity.

Eco-citizenship refers to the ecological awareness of belonging to an environment that guarantees its existence, which implies for it rights and duties in relation to a territory [20]. Each eco-citizen has the means to ensure sustainable development through his daily actions or to defend the idea with the authorities. That is to say, development that meets the needs of the present without com- 
promising those of future generations, that preserves human life and ecosystems, because both are intimately linked [20].

Changing individual ecological practices must become one of the main objectives, for the inhabitants as well as for the State. In addition, adopting a broad perspective on the relationship between the conditions of human settlements and health must require deep analysis.

\section{Limits}

Carrying out an insalubrity survey presupposes the observation of a large sample in order to generalise the results to the entire population. However, the size of the sample for this survey depends on the nature of the information you are looking for. However, depending on the choice one has to make, the methodological approach may have limits both in the data collection methods and in the information processing techniques. Thus, the sample size seems quite small for a populated district like Mombele. A larger number of sectors observed would undoubtedly have made it possible to refine the analysis in order to achieve a better generalisation of the results.

\section{Conclusions}

Urban management of waste is a broad field of investigation. To explore the different aspects of unhealthiness practices, we have chosen the Mombele district as a survey area. The fundamental concern that enabled us to carry out this study was to assess the behaviour/practices related to unsanitary conditions by the inhabitants of the Mombele district with a view to responsible behaviour change. To achieve the objectives, a sample of 384 respondents was selected whose statistical unit was the household. The key findings regarding these challenges are as follows:

- the characteristics of the respondents studied which predominated the sample were the level of secondary education, the socio-professional category/ occupation and a monthly income range of less than $\$ 100$. Household size average is 8 people per household;

- solid household waste management has proved to be the poor work of the population of the Mombele district, because the majority of respondents threw their household garbage anywhere when they went out without taking into account the potential nuisance or consequences on the environment and on health;

- the majority of respondents (52\%), has a positive attitude towards unsanitary conditions.

Therefore, in the present situation, we have found that the management of sanitation offers a good opportunity to explore this question in a relevant way.

\section{Recommendations}

Considering the behaviour towards insalubrity, the following recommendations are made: 
1) to introduce the environmental education in the education curriculum;

2) sanitation laws must be enforced on all citizenry.

\section{Current knowledge on the subject}

It should be noted that most of the works consulted addressing the issue of insalubrity (books, theses, dissertations, scientific journals, articles, etc.) mention that the problem of waste management and sanitation is an essential concern in developing countries where urbanisation is the source of many ills.

\section{Contribution of the study to knowledge}

- This study has allowed to identify the practices of the population of Mombele on unsanitary hygiene;

- The study therefore constitutes an advocacy for the development of rulers' policies for environmental education, allocation of budget to sanitation activities (household waste management) for the promotion of behaviour change.

\section{Acknowledgements}

We thank the entire population of Mombele district for participating in our study. Our thanks also go to the administrative authorities for their frank collaboration.

\section{Conflicts of Interest}

The authors declare no conflicts of interest regarding the publication of this paper.

\section{References}

[1] WHO (2016) Report of the World Health Organization.

[2] Matadi, J. (2017) The Management of Solid Household Waste in Tshikapa, Kasaï-Occidental: A Geo-Environmental and Socio-Economic Approach. Thesis in Geography, National Pedagogical University, Kinshasa.

[3] Savané, I. and Antoine, P. (1989) The Growth of Large Cities in West Africa: Examples from Dakar, Abidjan and Nouakchott. ORSTOM Congress, Dakar.

[4] Dorier-Apprill, E. (2006) City and Environment. Sedes, Paris.

[5] Sy, I. (2006) Communalisation and Development Problems: Analysis of Recent Changes in Ndioum. Master's Thesis in Geography, Cheikh Anta Diop University, Dakar.

[6] Limete, C. (2012) Archives of the Municipality of Limete. Unpublished.

[7] Munkuamo, G. (2016) Precariousness of the Urban Environment and Socio-Ethical Drifts in Kinshasa. DEA Thesis, Department of Environmental Sciences, Faculty of Sciences, UNIKIN, Kinshasa.

[8] PNDS (2011) National Health Development Plan.

[9] Mpuru, M. (2014) Le Kwilu: A Disputed Commercial Space? Bulletin Géographie de Kinshasa, 1, 57-77.

[10] Nzuzi, L. (2008) Kinshasa Ville et Environnement. Harmattan, Paris.

[11] UN-Habitat (2014) State of the World Population in 2014. Concise Report, United Nations, New York, 
[12] Banza Katshekewa, R. (2007) Perception of Risk Related to Unsanitary Housing in Urban Areas, DEA in Biology and Medicine, University of Lubumbashi, Lubumbashi.

[13] Binzangi, L. (2014) Reflections on the Evolution of the Environment of Kinshasa: From a Biospheric Portion to a Cupidosphere. Cahiers Congolais de l'Aménagement et du Bâtiment, IBTP, Kinshasa.

[14] Baya, R. (2006) Solid Household Waste Management in the City of Kinshasa, DEA Thesis, Department of Environmental Sciences, Faculty of Sciences, UNIKIN, Kinshasa.

[15] WHO (2003) Office of the WHO Representative for Congo Brazzaville. World Health Organisation, Geneva.

[16] Spizzichino, R. (2011) De la Ville en Politique. Harmattan, Paris.

[17] Reiss, C. (2020) Cable Car or Shared Taxis? Towards an Opening up of the Informal Districts of Medellín. Géoconfluences, Colombia.

[18] Lussault, M. and Lévy, J. (2003) Dictionary of Geography and the Space of Societies, Belin, Paris.

[19] Beucher, S. and Reghezza, M. (2005) Geography: Why? How? Hatier, Paris.

[20] Sauvé, L. (2017) Critical Dictionary of Educational Issues and Concepts. Harmattan, Paris. 